Artículo original

\title{
Caracterización epidemiológica de la infección por Leptospira spp. en caballos de trabajo y en personas ocupacionalmente expuestas en seis unidades de la Policía Nacional de Colombia
}

\author{
Juan Camilo Calderón ${ }^{1,2}$, Miryam Astudillo³, Marlyn H. Romero ${ }^{4}$ \\ ${ }^{1}$ Maestría en Salud Pública, Universidad de Caldas, Manizales, Colombia; Policía Nacional de \\ Colombia, Manizales, Colombia \\ ${ }^{2}$ Escuela de Ciencias Básicas, Universidad del Valle, Cali, Colombia \\ ${ }^{3}$ Grupo CIENVET, Departamento de Salud Animal, Facultad de Ciencias Agropecuarias, \\ Universidad de Caldas, Manizales, Colombia
}

Introducción. Los caballos de trabajo de la Policía Nacional tienen un estrecho contacto con sus manejadores y la población en general durante las actividades recreativas y de patrullaje, lo cual puede favorecer la transmisión de la leptospirosis en los caballos y el personal ocupacionalmente expuesto.

Objetivo. Caracterizar epidemiológicamente la leptospirosis mediante pruebas de serología, urocultivo y reacción en cadena de la polimerasa (Polymerase Chain Reaction, $\mathrm{PCR}$ ) en caballos de trabajo y personal con riesgo ocupacional pertenecientes a seis unidades de la Policía Nacional de Colombia.

Materiales y métodos. Se evaluaron 153 caballos machos castrados y 123 personas en las seis unidades en los municipios de Manizales, Pereira, Armenia, Ibagué, Tuluá y Cali. Se utilizaron tres formatos estructurados para recabar información y se obtuvieron muestras sanguíneas de las personas y de los caballos, las cuales se procesaron con la prueba de aglutinación microscópica (Macroscopic Agglutination Test, MAT) para 24 serogrupos. Se practicó el examen clínico de los caballos y se obtuvieron muestras de orina para el urocultivo y la PCR convencional.

Resultados. La seroprevalencia de Leptospira spp. fue de 3,25\% $(n=4)$ en las personas y de $85 \%(n=130)$ en los caballos. Entre los caballos, los serogrupos Djasiman y Shermani fueron los más prevalentes. El urocultivo fue positivo en el 64,7\% (99/153) de las muestras, en tanto que los análisis de PCR fueron negativos. Se encontró una asociación estadísticamente significativa de la frecuencia de salida de las instalaciones $(p=0,009)$ y la presencia de fauna silvestre $(p=0,051)$ con la infección por el serogrupo Shermani. Conclusión. Las características epidemiológicas de la leptospirosis en los caballos sugieren una presentación endémica de la infección y su papel como reservorios de la bacteria; sin embargo, debe dilucidarse la patogenia de la enfermedad con estudios complementarios.

Calderón JC, Astudillo M, Romero M. Caracterización epidemiológica de la infección por Leptospira spp. en caballos de trabajo y en personas ocupacionalmente expuestas en seis unidades de la Policía Nacional de Colombia. Biomédica. 2019;39(Supl.1):19-34 https://doi.org/10.7705/biomedica.v39i1.4475

Correspondencia:

Marlyn H. Romero, Departamento de Salud Animal, Facultad de Ciencias Agropecuarias, Universidad de Caldas, Calle 26 N $^{\circ} 66-10$, Manizales, Colombia Teléfono: (576) 8781500

marlyn.romero@ucaldas.edu.co

Contribución de los autores:

Juan Camilo Calderón: recolección de la información, análisis de laboratorio y estadístico

Myriam Astudillo: mantenimiento de las cepas de leptospiras y validación de las pruebas de laboratorio Marlyn H. Romero: dirección del proyecto, apoyo en la metodología y análisis estadístico

Todos los autores participaron en la escritura del manuscrito.

Financiación:

Este estudio fue financiado por la Vicerrectoría de Investigaciones y Posgrados de la Universidad de Caldas, por la Universidad del Valle, el Proyecto de Formación de Talento Humano de Alto Nivel del Tolima y la Policía Nacional de Colombia.

Palabras clave: Leptospira; leptospirosis/epidemiología; estudios seroepidemiológicos; factores de riesgo; caballos; pruebas de aglutinación; reacción en cadena de la polimerasa.

Epidemiological characterization of Leptospira spp. infection in working horses and in an occupationally exposed population in six Colombian police stations

Introduction: Police working horses are in close contact with their managers and the general population during recreational and patrol activities, which can favor the transmission of leptospirosis among the horses and the occupationally exposed personnel. Objective. To characterize epidemiologically leptospirosis through serology, urine culture and PCR in working horses and in the occupationally exposed population in six police stations in Colombia.

Materials and methods. We tested 153 castrated male horses and 123 people in six police stations in the municipalities of Manizales, Pereira, Armenia, Ibagué, Tuluá, and Cali. Three structured formats were applied and blood samples were obtained from people and horses, which were processed with the Macroscopic Agglutination Test, (MAT) for 24 serogroups. Horses were subject to a clinical examination, and urine samples were obtained for urine culture and conventional PCR.

Results. The seroprevalence of human Leptospira spp. was $3.25 \%(n=4)$ while in horses it was $85 \%(n=130)$. Among the horses, serogroups Djasiman and Shermani were the most prevalent. The urine culture was positive in $64.7 \%(99 / 153)$ of the samples, whereas PCR analyzes were negative. A statistically significant association was found between the frequency of exiting the facilities $(p=0.009)$ and the presence of wildlife $(p=0.0051)$ with the infection by serogroup Shermani. 
Conclusion. The epidemiological characteristics of leptospirosis in horses suggest an endemic presentation of the infection and its role as reservoirs of the bacteria; however, it is necessary to elucidate the pathogenesis of the disease with complementary studies.

Key words: Leptospira; leptospirosis/epidemiology; seroepidemiologic studies; risk factors; horses; agglutination test; polymerase chain reaction.

La leptospirosis es una enfermedad zoonótica de distribución global e importancia en salud pública (1). La seroprevalencia de la enfermedad en muchas partes del mundo se asocia con la infección renal crónica de una variedad de especies de animales domésticos, peridomésticos y de reservorios silvestres (2). El conocimiento de los serogrupos y los serovares prevalentes en un área es esencial para entender la epidemiología de la leptospirosis y adoptar medidas efectivas de control y erradicación de la enfermedad (3).

Los caballos tienen gran importancia económica y social en algunas partes del mundo por su papel en actividades como el transporte de carga y de pasajeros, el apoyo en las actividades agrícolas, la recreación, la ayuda en tratamientos médicos y el trabajo policial, entre otras actividades (4).

En algunos estudios recientes, se sugiere que la infección por Leptospira spp. en caballos se presenta en todo el mundo e involucra un amplio rango de serovares (2). La mayoría de las infecciones son de carácter subclínico y los animales pueden tener infección crónica de por vida (5). Cuando la enfermedad se manifiesta, los caballos presentan uveítis, abortos, nacimientos prematuros, mortinatos, problemas respiratorios, y disfunción hepática o renal (6). A diferencia de los animales, los seres humanos son huéspedes accidentales y adquieren la bacteria por contacto con fuentes ambientales infectadas (agua o suelo), o con animales silvestres y domésticos y sus secreciones, principalmente orina, o por la exposición ocupacional (7).

Los estudios serológicos en caballos son numerosos y han permitido establecer la exposición a las leptospiras y sus diferentes serovares (8). Además, es posible relacionar la serorreacción con signos clínicos como la uveítis y la inflamación no granulomatosa del iris, así como evaluar el riesgo de desarrollar ceguera (9).

Por su parte el urocultivo, una técnica de poca sensibilidad, pero de gran especificidad, tiene limitaciones por la dificultad de Leptospira spp. para crecer en medios artificiales y la probabilidad de contaminación del cultivo (10), cuyo crecimiento requiere que la bacteria esté presente con suficiente densidad en la muestra biológica, lo cual depende del grado de colonización renal y de la excreción permanente, condiciones que no se cumplen en todos los casos de infección renal (10).

La PCR se considera una prueba de gran sensibilidad y especificidad (11). La amplificación de los genes 165 o $23 S$ rARN se han empleado en estudios de leptospiras patógenas y saprofitas y en la detección rápida de la bacteria en un estadio temprano de la infección por la fácil obtención de los resultados y la posibilidad de usar diversos tipos de muestras (sangre, orina, humor acuoso o tejidos) (12,13). Sin embargo, esta técnica no identifica el serovar causante de la infección, aspecto que tiene un gran valor epidemiológico (14).

En Colombia, la leptospirosis humana es una enfermedad de notificación obligatoria en el Sistema de Vigilancia en Salud Pública (Sivigila) (15). La seroprevalencia de la leptospirosis humana en el país oscila entre el 6 y el $75,8 \%$ en la población general y en la ocupacionalmente expuesta $(15,16)$. En tres estudios de caballos, uno en la Sabana de Bogotá, uno en Santander 
y otro en la región del Meta y el Guaviare, se registraron seroprevalencias entre el 40,4 y el $76,6 \%$ (17).

Los caballos usados para el trabajo policial viven en estrecho contacto con sus manejadores y con la población general, durante las actividades recreativas, de patrullaje y de control del orden público. Asimismo, son trasladados a diferentes unidades como apoyo en actividades con otros caballos, lo que aumenta el riesgo de exposición a Leptospira spp. y los convierte en una fuente de infección para humanos y otros animales propensos a la infección (18).

En este contexto, el objetivo del presente estudio fue caracterizar la epidemiología de la leptospirosis mediante serología, urocultivo y PCR convencional en caballos de trabajo y en la población con riesgo ocupacional en seis unidades de policía de Colombia, y evidenciar el papel potencial de los caballos en la transmisión de este microorganismo.

\section{Materiales y métodos}

Se llevó a cabo un estudio de prevalencia, el cual fue aprobado por el Comité de Ética de la Universidad de Caldas (Acta Nº 011 de junio de 2016 del Comité de Bioética y Acta $N^{\circ} 02$ de junio de 2016 del Comité de Ética para la Experimentación con Animales). Asimismo, el estudio se ajustó a lo establecido en las normas éticas para el manejo de animales de laboratorio de la Ley 84 de 1989 y el Decreto 2257 de 1986.

Se obtuvo la autorización de la Policía Nacional para la toma de las muestras biológicas de los caballos y el consentimiento informado de los participantes en este mismo sentido.

\section{Localización geográfica}

La Policía cuenta con 25 unidades policiales en el territorio nacional, en las cuales se mantienen 2.700 caballos. De estas, se seleccionaron $6(24 \%)$ cuyas características climáticas (clima cálido y condiciones húmedas) favorecen la supervivencia de las leptospiras y que presentaban antecedentes previos de serorreacción (14).

Se evaluaron las unidades de los municipios de Manizales (altura de 2.170 m.s.n.m., temperatura media anual de $17^{\circ} \mathrm{C}$ y precipitación anual de $2.358 \mathrm{~mm}$ ), Pereira (altura de 1.411 m.s.n.m., temperatura media anual de $28{ }^{\circ} \mathrm{C}$ y precipitación anual de $2.750 \mathrm{~mm}$ ), Armenia (altura de 1.229 m.s.n.m., temperatura media anual de $22^{\circ} \mathrm{C}$ y precipitación anual de $2.164 \mathrm{~mm}$ ), lbagué (altura de 928 m.s.n.m., temperatura media anual de $24^{\circ} \mathrm{C}$ y precipitación anual de $1.691 \mathrm{~mm}$ ), Tuluá (altura de 960 m.s.n.m., temperatura media anual de $24{ }^{\circ} \mathrm{C}$ y precipitación anual de $1.300 \mathrm{~mm}$ ) y Cali (altura de 985 m.s.n.m., temperatura media anual de $24^{\circ} \mathrm{C}$ y precipitación anual de $1.483 \mathrm{~mm}$ ) (figura 1).

\section{Población de estudio y tamaño de la muestra}

La población de estudio incluyó 267 personas (carabineros, preparadores, enfermeros y cuidadores de los caballos) y 263 caballos (machos castrados; en las unidades seleccionadas no había hembras) destinados a las labores de patrullaje rural y urbano y de diferentes razas (silla argentino, percherón, belga, pura sangre inglés, silla francés, criollo colombiano y cruces de estas razas), con edades entre los 4 y los 23 años. 


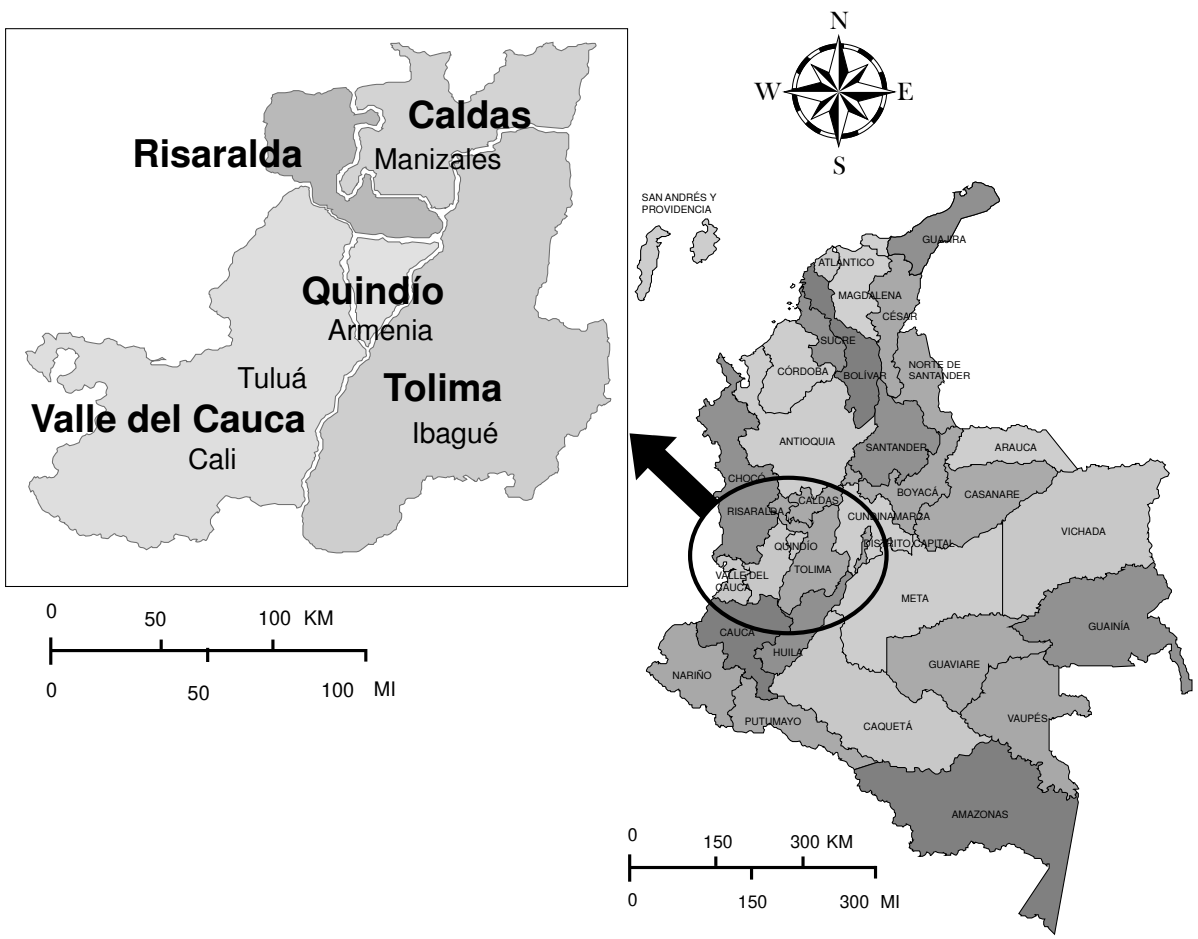

Figura 1. Localización geográfica de las unidades policiales incluidas en el estudio

Las muestras se seleccionaron de forma aleatoria, estratificada y proporcional, tomando como referencia seroprevalencias nacionales de infección del $18 \%$ en humanos $(n=123)(16,17)$ y de $40 \%$ en caballos $(n=153)$ (18). En ambos casos, se consideró un error y una significación del $5 \%$.

Las fórmulas utilizadas para los cálculos se presentan a continuación (19).

Para el tamaño de muestra:

$$
n=\frac{\frac{\left(\sum_{h=1}^{H} W_{h} \sqrt{p_{h} q_{h}}\right)^{2}}{\delta^{2} / z^{2}}}{1+\frac{1}{N * \delta^{2} / z^{2}} \sum_{h=1}^{H} W_{h} p_{h} q_{h}},
$$

donde $\mathrm{z}$ corresponde al valor de $\mathrm{Z}$ que deja un área a la derecha, al tamaño del error: al peso del estrato $=\mathrm{Nh} / \mathrm{N}, \mathrm{N}$ el tamaño de la población, $\mathrm{n}$ al tamaño de la muestra, ph a la proporción del estrato, y qh a (1-ph), y

para la distribución por estratos:

$$
n_{h}=n \frac{W_{h} \sqrt{p_{h} q_{h}}}{\sum_{h=1}^{H} W_{h} \sqrt{p_{h} q_{h}}}
$$

Los criterios de inclusión de los humanos fueron tener contacto directo con los caballos durante sus labores y llevar laborando en las remontas no menos de tres meses. Se excluyeron aquellos caballos que habían permanecido en la remonta por menos de tres meses, período necesario para que los resultados de las pruebas diagnósticas usadas en el estudio evidenciaran el contacto entre las personas y los caballos de cada unidad policial, ya que los títulos de anticuerpos aparecen en los animales siete días después de los primeros síntomas (14). 


\section{Examen clínico}

Un médico veterinario especialista en medicina equina examinó detenidamente a los caballos al inicio del estudio y revisó de forma exhaustiva las historias clínicas con los reportes de los últimos dos años para establecer si se habían hecho exámenes de laboratorio y si se habían presentado síntomas relacionados con la leptospirosis (6,9). Esta información se consignó en un formato que fue validado mediante una prueba piloto en la unidad policial de Cali y por expertos en leptospirosis.

\section{Factores de riesgo}

Se utilizaron dos formatos estructurados y validados. En el primero, se evaluaron las variables demográficas y sanitarias, el manejo de los caballos y la presencia de especies silvestres, mediante visitas a las instalaciones, observación directa y entrevistas al personal responsable. El segundo fue un cuestionario dirigido a los participantes en el estudio para conocer su edad, el cargo, el contacto con fluidos de los caballos, las normas de bioseguridad y las conductas de manejo de los animales según los parámetros establecidos a partir de consultas con profesores expertos de la Universidad de Caldas, así como de la prueba piloto desarrollada en la unidad policial de Cali.

\section{Muestras sanguíneas y prueba de microaglutinación}

Se obtuvieron $5 \mathrm{ml}$ de sangre por punción de la vena yugular de los caballos y de la cefálica de los humanos, que luego se centrifugaron durante cinco minutos a $3.500 \mathrm{rpm}$. Los sueros se almacenaron a $2{ }^{\circ} \mathrm{C}$ para el transporte al laboratorio y se congelaron a $-5^{\circ} \mathrm{C}$ hasta el momento del análisis, efectuado 15 días después del muestreo.

Las muestras se procesaron en el Laboratorio de Diagnóstico de Leptospirosis de la Universidad del Valle en Cali. En el mantenimiento de las cepas y el manejo de la técnica de microaglutinación (MAT). se siguieron los parámetros convencionales (17), utilizando un cepario de referencia suministrado por el laboratorio internacional de referencia para el diagnóstico de la leptospirosis del Royal Tropical Institute (Ámsterdam, Holanda).

Se consideraron como positivos los sueros de los humanos con títulos iguales o mayores de 1:160 y, para los caballos, aquellos sueros con títulos iguales o mayores de 1:100 (20). El grado de reacción se estableció estimando los porcentajes de leptospiras que aglutinaron.

\section{Urocultivo}

Las muestras de orina de los caballos se obtuvieron en las remontas siguiendo estrictas normas de bioseguridad. Se indujo la micción, se recolectaron $15 \mathrm{ml}$ y se obtuvo una alícuota de $1 \mathrm{ml}$ que se cultivó de inmediato en el medio Ellinghausen-McCullough-Johnson-Harris (EMJH) (17) (Becton Dickinson and Company, Difco) (21).

Las muestras se mantuvieron a temperatura ambiente en neveras de icopor, para protegerlas de la luz solar. En el laboratorio, se incubaron a 30 ${ }^{\circ} \mathrm{C}$, durante un período máximo de cuatro meses hasta el momento en que las espiroquetas se observaron al microscopio. Las muestras cultivadas se sembraron de nuevo en el medio de cultivo de EMJH, y se agregaron $500 \mu \mathrm{l}$ del cultivo primario y $1 \%$ de 5 -fluorouracilo. 
Sin tener en cuenta el resultado de la lectura, se hicieron siembras para controlar la contaminación bacteriana y favorecer el crecimiento de las espiroquetas. Se hicieron observaciones semanales bajo el microscopio de campo oscuro (Nikon $\mathrm{BH} 2$ ) tomando $10 \mu \mathrm{l}$ del cultivo y visualizando toda la placa para verificar la presencia de espiroquetas. La prueba se consideró positiva pasadas 16 semanas si se observaban, como mínimo, cuatro espiroquetas por placa en alguno de los urocultivos (2).

\section{Reacción en cadena de la polimerasa}

Se obtuvo $1 \mathrm{ml}$ del urocultivo y se siguieron las instrucciones del QIAamp DNA Mini Kit ${ }^{T M}$ (Qiagen). Se hizo una PCR convencional simple utilizando los iniciadores descritos por Levett (11): LipL32/270f (5'-CGCTGAAATGGGAGTTCGTATGATT-3') y LipL32/692R (5' -CCAACAGATGCAACGAAAGATCCTTT-3'), dirigidos a una región ubicada entre las posiciones 270 y 692 del gen lipL32, el cual codifica para la lipoproteína de membrana LipL32, siguiendo los lineamientos descritos por Moreno, et al. (22).

Se usó como control positivo Leptospira interrogans, serovar Canicola, cepa Hond Utrecht IV (77.8 ng/ $\mathrm{\mu l})$, y como controles negativos, Bacillus cereus, Enterococcus faecalis, Salmonella Typhimurium y Listeria monocytogenes, suministrados por el área de bacteriología del Laboratorio de Microbiología de la Universidad del Valle.

\section{Análisis estadístico}

Se hizo un estudio descriptivo para analizar las variables consideradas como factores de riesgo. Se estableció la seroprevalencia de la infección en las dos poblaciones estudiadas y se hizo un análisis de regresión logística bivariada que asumió, como variable de respuesta binomial, los resultados de la prueba MAT, donde 0 correspondió a los sueros con resultados negativos y 1 a los sueros positivos. Además, se hizo la prueba de bondad de ajuste del modelo obtenido mediante la prueba de Hosmer y Lemeshow.

Los efectos de las variables de predicción del resultado positivo o negativo de la prueba, se expresaron mediante razones de disparidad (OR) y sus respectivos intervalos de confianza del $95 \%$. Los valores de $p$ menores de 0,05 se consideraron como significativos. El modelo para humanos consideró todos los serogrupos positivos en la prueba MAT; en los caballos, se hicieron dos análisis para los serogrupos más prevalentes en las remontas (Shermani y Djasiman). El análisis se efectúo utilizando el programa Stata ${ }^{\mathrm{TM}}$, versión 13.0 (College Station, Texas, USA).

\section{Resultados}

\section{Examen clínico}

El 83,7\% (128/153) de los caballos tenía una condición corporal normal, el 10,5\% (16/153) estaba delgado, el 4,5\% (7/153) tenía sobrepeso y el 1,3 $\%(2 / 153)$ estaba caquéctico.

En el examen clínico, el 10,5 \% (16/153) de los caballos presentó alteraciones en el sistema tegumentario, pues se encontraron laceraciones (63 $\%)$, costras y alopecia (37\%), además de afecciones oculares $(6,5 \%, 10 / 153)$, como atrofia (10\%), queratitis (10\%), opacidad corneal (50\%), epífora y uveítis (30\%). Por último, se presentaron trastornos en el sistema locomotor 
en el $5,9 \%(9 / 153)$ de los ejemplares, y se observaron claudicaciones (44 \%), hormiguillos (22\%), linfangitis (11\%) e inflamaciones osteoarticulares (22\%).

\section{Antecedentes clínicos de los caballos}

En la evaluación de los antecedentes en las historias clínicas, en el 84,3 $\%(129 / 153)$ de los caballos no se habían reportado signos relacionados con un cuadro clínico de leptospirosis (fiebre, anorexia, anemia petequial, ictericia o intolerancia al ejercicio) (2). El 8,5\% (13/153) había presentado fiebre, el $4,6 \%(7 / 153)$, decaimiento, el $0,7 \%(1 / 153)$, pérdida de peso crónica o disuria y el $5,9 \%(9 / 153)$ había tenido trastornos oculares.

\section{Seroprevalencia en humanos}

La seroprevalencia de leptospirosis humana fue de 3,25\% (4/123) $\left(\mathrm{IC}_{95 \%}\right.$ 2-4,5): dos casos de la remonta de Cali, con títulos de 1:160 (serotipos Canicola, Panamá y Shermani) y los dos restantes de Pereira (serotipos Grippotyphosa, Bataviae, Autumnalis y Sejroe), con títulos entre 1:160 y 1:2.560. Las coaglutinaciones entre los serovares fue de 1,6\%(2/123).

\section{Seroprevalencia en caballos}

La seroprevalencia general establecida mediante la prueba MAT en los caballos fue del $85 \%(130 / 153)\left(\mathrm{IC}_{95 \%} 79-91\right)$. En la figura 2 se presenta la distribución de la serorreacción de los anticuerpos contra Leptospira spp. de los caballos en las seis unidades policiales estudiadas. El 7,8 \% ( $n=12)$ de los sueros fue reactivo a un solo serogrupo y el resto presentó títulos frente a dos o más serogrupos. El $62 \%$ de los sueros presentó títulos de 800 o mayores. No se encontraron diferencias significativas entre las seroprevalencias $(p=0,979)$. Los serogrupos encontrados en los caballos se muestran en los cuadros 1 y 2 .

\section{Urocultivo}

La frecuencia hallada en el urocultivo fue de 64,7 \% (99/153) $\left(\mathrm{IC}_{95 \%}: 57-\right.$ 72). Se observaron espiroquetas en todas las remontas: en Tuluá, 83,3 \% (15/18); en Pereira, $80 \%$ (16/20); en Ibagué, 69,5 \% (16/23); en Manizales, $63,4 \%$ (26/41); en Armenia, 53,3 \% (8/15), y en Cali, $50 \%$ (18/36), sin que se registraran diferencias significativas $(p=0,921)$.

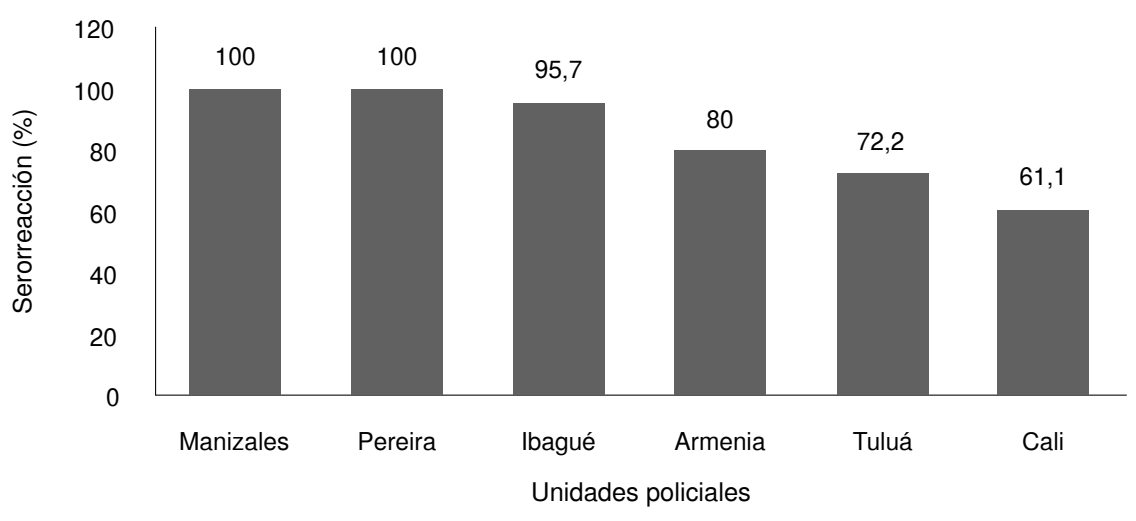

Figura 2. Serorreacción de los anticuerpos de los caballos contra Leptospira spp. en seis unidades de la Policía Nacional de Colombia 
Cuadro 1. Seroprevalencia $(P)$ de serogrupos de Leptospira spp. en caballos de las remontas de Cali $(n=122)$, Tuluá $(n=88)$ y Armenia $(n=73)$, Colombia

\begin{tabular}{|c|c|c|c|c|c|c|}
\hline \multirow[b]{2}{*}{ Serogrupos } & \multicolumn{2}{|r|}{ Cali $^{\star}$} & \multicolumn{2}{|c|}{ Tuluá* } & \multicolumn{2}{|c|}{ Armenia* } \\
\hline & $\begin{array}{l}\text { Número de } \\
\text { títulos } \\
(\geq 1: 100)\end{array}$ & $\begin{array}{l}\text { p (\%) } \\
\text { IC }_{95 \%}\end{array}$ & $\begin{array}{l}\text { Número de } \\
\text { títulos } \\
(\geq 1: 100)\end{array}$ & $\begin{array}{l}\text { p (\%) } \\
\text { IC }_{95 \%}\end{array}$ & $\begin{array}{c}\text { Número de } \\
\text { títulos } \\
(\geq 1: 100)\end{array}$ & $\begin{array}{l}\text { p (\%) } \\
\text { IC }_{95 \%}\end{array}$ \\
\hline Djasiman & 14 & $11,5(5,8-17,1)$ & 9 & $10,2(3,9-16,6)$ & 8 & $11,0(3,8-18,1)$ \\
\hline Pomona & 12 & $9,8(4,6-15,1)$ & 7 & $8,0(2,3-13,6)$ & 7 & $9,6(2,8-16,3)$ \\
\hline Hebdomadis & 11 & $9,0(3,9-14,1)$ & 6 & $6,8(1,6-12,1)$ & 4 & $5,5(0,3-10,7)$ \\
\hline Autumnalis & 10 & $8,2(3,3-14,1)$ & 7 & $8,0(2,3-13,6)$ & 4 & $5,5(0,3-10,7)$ \\
\hline Canicola & 7 & $5,7(1,6-9,9)$ & 6 & $6,8(1,6-12,1)$ & 5 & $6,8(1,1-12,6)$ \\
\hline Hurstbridge & 9 & $7,4(2,7-12,0)$ & 5 & $5,7(0,8-10,5)$ & 4 & $5,5(0,3-10,7)$ \\
\hline Cynopteri & 8 & $6,6(2,2-10,9)$ & 5 & $5,7(0,8-10,5)$ & 4 & $5,5(0,3-10,7)$ \\
\hline Louisiana & 10 & $8,2(3,3-13,1)$ & 4 & $4,5(0,2-8,9)$ & 3 & $4,1(0,4-8,7)$ \\
\hline Panama & 8 & $6,6(2,2-10,9)$ & 3 & $3,4(0-7,2)$ & 6 & $8,2(1,9-14,5)$ \\
\hline Australis & 5 & $4,1(7,6-0,6)$ & 3 & $3,4(0-7,2)$ & 3 & $4,1(0,4-8,7)$ \\
\hline Semaranga & 2 & $1,6(0-3,9)$ & 6 & $6,8(1,6-12,1)$ & 4 & $5,5(0,3-10,7)$ \\
\hline Ballum & 4 & $3,3(0,1-6,4)$ & 2 & $2,3(0-5,4)$ & 4 & $5,5(0,3-10,7)$ \\
\hline Bataviae & 4 & $3,3(0,1-6,4)$ & 4 & $4,5(0-8,9)$ & 1 & $1,4(0-4,0)$ \\
\hline Tarassovi & 1 & $0,8(0-2,4)$ & 5 & $5,7(0-10,5)$ & 3 & $4,1(0,4-8,7)$ \\
\hline Shermani & 1 & $0,8(0-2,4)$ & 5 & $5,7(0-10,5)$ & 3 & $4,1(0,4-8,7)$ \\
\hline Manhao & 3 & $2,5(0-5,2)$ & 2 & $2,3(0-5,4)$ & 2 & $2,7(0-6,5)$ \\
\hline Sarmin & 3 & $2,5(0-5,2)$ & 3 & $3,4(0-7,2)$ & 1 & $1,4(0-4,0)$ \\
\hline Grippotyphosa & 3 & $2,5(0-5,2)$ & 2 & $2,3(0-5,4)$ & 1 & $1,4(0-4,0)$ \\
\hline Pyrogenes & 1 & $0,8(0-2,4)$ & 2 & $2,3(0-5,4)$ & 2 & $2,7(0-6,5)$ \\
\hline Celledoni & 1 & $0,8(0-2,4)$ & 2 & $2,3(0-5,4)$ & 1 & $1,4(0-4,0)$ \\
\hline Ranarum & 2 & $1,6(0-3,9)$ & 0 & $0,0(0-0)$ & 2 & $2,7(0-6,5)$ \\
\hline Icterohaemorrhagiae & 2 & $1,6(0-3,9)$ & 0 & $0,0(0-0)$ & 0 & $0,0(0-0)$ \\
\hline Mini & 1 & $0,8(0-2,4)$ & 0 & $0,0(0-0)$ & 0 & $0,0(0-0)$ \\
\hline Sejroe & 0 & $0,0(0-0)$ & 0 & $0,0(0-0)$ & 1 & $1,4(0-4,0)$ \\
\hline
\end{tabular}

* Número de títulos positivos para todos los serogrupos evaluados (desde 100 hasta 3.200)

IC: intervalo de confianza del $95 \%$

\section{Reacción en cadena de la polimerasa}

Se obtuvo una amplificación de 423 pb para un fragmento de LipL32 en el control positivo de $L$. interrogans serovar Canicola cepa Hond Utrecht IV, en tanto que las muestras de los controles negativos no tuvieron reacciones. Sin embargo, no se obtuvieron reacciones específicas para el gen LipL32 en ninguno de los urocultivos.

\section{Factores de riesgo en humanos}

El personal evaluado tenía contacto permanente con los caballos y el $87,6 \%(n=108)$ usaba barreras de protección personal, como guantes, tapabocas y estrictas normas de bioseguridad. Tres de las cuatro personas que presentaron títulos contra Leptospira spp. tenían contacto con fluidos de los caballos, pero no se encontró ninguna asociación entre la infección y las variables incluidas en el análisis (cuadro 3). 
Cuadro 2. Seroprevalencia de serogrupos de Leptospira spp. en caballos de remontas de Manizales ( $n=401)$, Ibagué $(n=199)$ y Pereira $(n=163)$, Colombia

\begin{tabular}{|c|c|c|c|c|c|c|}
\hline \multirow[b]{2}{*}{ Serogrupos } & \multicolumn{2}{|c|}{ Manizales* } & \multicolumn{2}{|c|}{ Ibagué* } & \multicolumn{2}{|c|}{ Pereira* } \\
\hline & $\begin{array}{l}\text { Número de } \\
\text { títulos } \\
(\geq 1: 100)\end{array}$ & $\begin{array}{l}\text { p (\%) } \\
\text { IC }_{95 \%}\end{array}$ & $\begin{array}{l}\text { Número de } \\
\text { títulos } \\
(\geq 1: 100)\end{array}$ & $\begin{array}{l}\text { p (\%) } \\
\text { IC }_{95 \%}\end{array}$ & $\begin{array}{c}\text { Número de } \\
\text { títulos } \\
(\geq 1: 100)\end{array}$ & $\begin{array}{l}\text { p (\%) } \\
I C_{95 \%}\end{array}$ \\
\hline Shermani & 32 & $8,0(5,3-10,6)$ & 17 & $8,5(4,7-12,4)$ & 15 & $9,2(4,8-13,6)$ \\
\hline Tarassovi & 32 & $8,0(5,3-10,6)$ & 15 & $7,5(3,9-11,2)$ & 15 & $9,2(4,8-13,6)$ \\
\hline Djasiman & 30 & $7,5(4,9-10,1)$ & 18 & $9,0(5,1-13,0)$ & 13 & $8,0(3,8-12,1)$ \\
\hline Hurstbridge & 33 & $8,2(5,5-10,9)$ & 14 & $7,0(3,5-10,6)$ & 11 & $6,7(2,9-10,6)$ \\
\hline Semaranga & 28 & $7,0(4,5-9,5)$ & 13 & $6,5(3,1-10,0)$ & 13 & $8,0(3,8-12,1)$ \\
\hline Hebdomadis & 29 & $7,2(4,7-9,8)$ & 13 & $6,5(3,1-10,0)$ & 8 & $4,9(1,6-8,2)$ \\
\hline Cynopteri & 27 & $6,7(4,3-9,2)$ & 14 & $7,0(3,5-10,6)$ & 9 & $5,5(2,0-9,0)$ \\
\hline Australis & 25 & $6,2(3,9-8,6)$ & 11 & $5,5(2,4-8,7)$ & 9 & $5,5(2,0-9,0)$ \\
\hline Autumnalis & 21 & $5,2(3,1-7,4)$ & 8 & $4,0(1,3-6,7)$ & 8 & $4,9(1,6-8,2)$ \\
\hline Pomona & 16 & $4,0(2,1-5,9)$ & 13 & $6,5(3,1-10,0)$ & 8 & $4,9(1,6-8,2)$ \\
\hline Panama & 17 & $4,2(2,3-6,2)$ & 11 & $5,5(2,4-8,7)$ & 6 & $3,7(0,8-6,6)$ \\
\hline Canicola & 15 & $3,7(1,9-5,6)$ & 9 & $4,5(1,6-7,4)$ & 6 & $3,7(0,8-6,6)$ \\
\hline Pyrogenes & 15 & $3,7(1,9-5,6)$ & 5 & $2,5(0,3-4,7)$ & 10 & $6,1(2,5-9,8)$ \\
\hline Louisiana & 13 & $3,2(1,5-5,0)$ & 8 & $4,0(1,3-6,7)$ & 4 & $2,5(0,1-4,8)$ \\
\hline Ballum & 10 & $2,5(1,0-4,0)$ & 5 & $2,5(0,3-4,7)$ & 6 & $3,7(0,8-6,6)$ \\
\hline Sarmin & 12 & $3,0(1,3-4,7)$ & 5 & $2,5(0,3-4,7)$ & 6 & $3,7(0,8-6,6)$ \\
\hline Bataviae & 12 & $3,0(1,3-4,7)$ & 6 & $3,0(0,6-5,4)$ & 3 & $1,8(0-3,9)$ \\
\hline Ranarum & 12 & $3,0(1,3-4,7)$ & 5 & $2,5(0,3-4,7)$ & 2 & $1,2(0-2,9)$ \\
\hline Mini & 7 & $1,7(0,5-3,0)$ & 5 & $2,5(0,3-4,7)$ & 3 & $1,8(0-3,9)$ \\
\hline Manhao & 5 & $1,2(0,2-2,3)$ & 2 & $1,0(0-2,4)$ & 4 & $2,5(0,1-4,8)$ \\
\hline Grippotyphosa & 4 & $1,0(0-2,0)$ & 0 & $0,0(0-0)$ & 1 & $0,6(0-1,8)$ \\
\hline Icterohaemorrhagiae & 2 & $0,5(0-1,2)$ & 1 & $0,5(0-1,5)$ & 1 & $0,6(0-1,8)$ \\
\hline Sejroe & 2 & $0,5(0-1,2)$ & 1 & $0,5(0-1,5)$ & 1 & $0,6(0-1,8)$ \\
\hline Celledoni & 2 & $0,5(0-1,2)$ & 0 & $0,0(0-0)$ & 1 & $0,6(0-1,8)$ \\
\hline
\end{tabular}

* Número de títulos positivos para todos los serogrupos evaluados (desde 100 hasta 3.200)

IC: intervalos de confianza del $95 \%$

\section{Factores de riesgo en caballos}

Leptospira Shermani fue el serogrupo más prevalente en las remontas de Manizales, Ibagué y Pereira. Los animales de fauna silvestre reportados por el personal en las remontas fueron zarigüeyas (Didelphimorphia), zorrillos (Mephitidae), armadillos (Dasypodidae), conejos (Oryctolagus cuniculus), ardillas (Sciurus vulgaris), iguanas (Iguana iguana) y serpientes, cuyos ejemplares no se capturaron y no se sometieron a ningún procedimiento. La evaluación de los factores de riesgo asociados al serogrupo Shermani se presenta en el cuadro 4.

El serogrupo de mayor seroprevalencia para las remontas de Cali, Tuluá y Armenia, fue el Djasiman y los resultados del análisis logístico binario de la infección por dicho serogrupo se presentan en el cuadro 5. 
Cuadro 3. Análisis de regresión logística binaria de las variables evaluadas en la población humana positiva para Leptospira spp. en remontas de seis municipios colombianos

\begin{tabular}{|c|c|c|c|c|c|}
\hline Variable & $\mathbf{n}$ & $\begin{array}{c}\text { Títulos } \geq 1: 100 \\
\mathrm{n}(\%)\end{array}$ & p & OR & IC $_{95 \%}$ \\
\hline \multicolumn{6}{|l|}{ Sexo } \\
\hline Masculino & 116 & $3(2,6)$ & 0,135 & 0,2 & $0,0-1,8$ \\
\hline Femenino & 7 & $1(14,2)$ & & & \\
\hline \multicolumn{6}{|l|}{ Edad (años) } \\
\hline $24-30$ & 47 & $1 \quad(2,1)$ & 0,428 & 0,9 & $0,7-1,1$ \\
\hline $31-37$ & 49 & $3(6,1)$ & & & \\
\hline $38-55$ & 27 & 0 & & & \\
\hline \multicolumn{6}{|l|}{ Cargo } \\
\hline Médico veterinario & 3 & 0 & 1,00 & 1,0 & $0,8-1,2$ \\
\hline Enfermero veterinario & 9 & 0 & & & \\
\hline Preparador & 2 & 0 & & & \\
\hline Carabinero & 86 & $3(3,5)$ & & & \\
\hline Auxiliar de remonta & 7 & $1(14,2)$ & & & \\
\hline Herrero & 9 & 0 & & & \\
\hline Servicio de caballada & 7 & 0 & & & \\
\hline \multicolumn{6}{|c|}{$\begin{array}{l}\text { Tiempo en la unidad en la que } \\
\text { labora (años) }\end{array}$} \\
\hline $1-6$ & 89 & $3(3,4)$ & 0,892 & 1,0 & $0,8-1,2$ \\
\hline $7-13$ & 26 & $1 \quad(3,8)$ & & & \\
\hline$\geq 14$ & 8 & 0 & & & \\
\hline \multicolumn{6}{|c|}{ Contacto con fluidos de los caballos } \\
\hline Sí & 105 & $3(2,8)$ & 0,558 & 2,0 & $0,2-20,4$ \\
\hline No & 18 & $1 \quad(5,5)$ & & & \\
\hline \multicolumn{6}{|c|}{ Uso de medidas de bioseguridad } \\
\hline Sí & 107 & $4(3,7)$ & 0,999 & 1,0 & $0,8-1,2$ \\
\hline No & 16 & 0 & & & \\
\hline \multicolumn{6}{|l|}{ Baño reciente en un río } \\
\hline Sí & 37 & $3(8,1)$ & 0,086 & 0,133 & $0,0-1,3$ \\
\hline No & 86 & $1 \quad(1,2)$ & & & \\
\hline \multicolumn{6}{|c|}{ Presencia de perros en casa } \\
\hline Sí & 63 & $3(4,8)$ & 0,355 & 0,339 & $0,0-3,4$ \\
\hline No & 60 & $1 \quad(1,7)$ & & & \\
\hline
\end{tabular}

IC: intervalos de confianza; OR: razón de disparidad

\section{Discusión}

A pesar de que los reportes de la transmisión de leptospiras patógenas de los caballos a otros animales y al ser humano son escasos, la seropositividad sí es frecuente, con valores altos y títulos variables según los diferentes serotipos (13), lo cual se confirmó en el presente trabajo.

Algunos autores han sugerido que los caballos son huéspedes de mantenimiento y tienen la capacidad de eliminar las leptospiras en la orina durante largos periodos $(2,6)$. Sin embargo, se encontró que el 3,25 \% del personal ocupacionalmente expuesto en las remontas, tenía anticuerpos contra Leptospira spp. Esta baja frecuencia podría deberse a la prevención mediante barreras de protección personal al tener contacto con los fluidos de los caballos y a las medidas de bioseguridad, cuya inobservancia representa un riesgo de contraer la enfermedad (7).

En cuanto a la transmisibilidad, no se sabe si las condiciones de supervivencia de las leptospiras en el riñón de los caballos alteran la fisiología de la bacteria reduciendo su patogenia, o si hay diferencias de transmisibilidad entre machos y hembras, lo que no se comprobó dado que no se incluyeron yeguas en el estudio (13). 
Cuadro 4. Análisis de regresión logística binaria de las variables evaluadas en la población humana positiva para Leptospira spp. en remontas de seis municipios colombianos

\begin{tabular}{|c|c|c|c|c|c|}
\hline Variable & $\mathbf{n}$ & $\begin{array}{c}\text { Títulos } \geq 1: 100 \\
\mathrm{n}(\%)\end{array}$ & $\mathbf{p}$ & OR & IC $_{95 \%}$ \\
\hline Edad (años) & & & 0,008 & 1,1 & $0,1-1,2$ \\
\hline 3-7 & 18 & $8(44,4)$ & & & \\
\hline $8-12$ & 102 & $49(48,0)$ & & & \\
\hline$\geq 13$ & 33 & $22(66,6)$ & + & & \\
\hline Frecuencia de salida & & & 0,008 & 1,1 & $0,1-1,2$ \\
\hline No sale & 15 & $3(20,0)$ & & & \\
\hline 1 vez por semana & 18 & $6(33,3)$ & & & \\
\hline 2 veces por semana & 22 & $10(45,4)$ & & & \\
\hline 3 veces por semana & 42 & $27(64,2)$ & & & \\
\hline 4 veces por semana & 46 & $30(65,2)$ & & & \\
\hline 5 veces por semana & 10 & $3(30,0)$ & + & & \\
\hline Temperatura & & & 0,000 & 0,7 & $0,6-0,8$ \\
\hline Baja $\left(17^{\circ} \mathrm{C}\right)$ & 41 & $34(83,0)$ & & & \\
\hline Media $\left(22^{\circ} \mathrm{C}\right)$ & 35 & $19(54,2)$ & & & \\
\hline Alta $\left(24^{\circ} \mathrm{C}\right)$ & 77 & $26(33,8)$ & + & & \\
\hline $\begin{array}{l}\text { Almacenamiento de alimento } \\
\text { concentrado }\end{array}$ & & & 0,000 & 20,6 & $8,5-49,8$ \\
\hline Malo & 84 & $67(79,7)$ & & & \\
\hline Bueno & 69 & $12(17,4)$ & + & & \\
\hline Presencia de fauna silvestre & & & 0,051 & 3,3 & $1,0-10,8$ \\
\hline Sí & 138 & $75(54,3)$ & + & & \\
\hline No & 15 & $4(26,6)$ & & & \\
\hline
\end{tabular}

IC: intervalos de confianza, OR: razón de disparidad

+: Variables de las respuestas con un nivel de significación de 0,05\%

Cuadro 5. Análisis de regresión logística binaria de las variables asociadas con la serorreacción al serovar Djasiman en remontas de seis municipios colombianos

\begin{tabular}{|c|c|c|c|c|c|}
\hline Variable & $\mathbf{n}$ & $\begin{array}{c}\text { Títulos } \geq 1: 100 \\
n(\%)\end{array}$ & $\mathbf{p}$ & OR & IC $_{95 \%}$ \\
\hline Frecuencia de salida & & & 0,004 & 1,4 & $1,1-1,8$ \\
\hline No sale & 15 & $4(26,7)$ & & & \\
\hline 1 vez por semana & 18 & $6(33,3)$ & & & \\
\hline 2 veces por semana & 22 & $13(59,1)$ & & & \\
\hline 3 veces por semana & 42 & $29(69,0)$ & & & \\
\hline 4 veces por semana & 46 & $28(60,1)$ & & & \\
\hline 5 veces por semana & 10 & $7(70,0)$ & + & & \\
\hline Temperatura & & & 0,001 & 0,8 & $0,7-0,9$ \\
\hline Baja $\left(17^{\circ} \mathrm{C}\right)$ & 41 & $32(78,0)$ & & & \\
\hline Media $\left(22^{\circ} \mathrm{C}\right)$ & 35 & $21 \quad(60,0)$ & & & \\
\hline Alta $\left(24^{\circ} \mathrm{C}\right)$ & 77 & $34(44,1)$ & + & & \\
\hline $\begin{array}{l}\text { Almacenamiento de alimento } \\
\text { concentrado }\end{array}$ & & & 0,000 & 8,5 & $2,6-28,6$ \\
\hline Malo & 84 & $65(77,3)$ & + & & \\
\hline Bueno & 69 & $22(31,9)$ & & & \\
\hline
\end{tabular}

IC: intervalos de confianza, OR: razón de disparidad

+: Variables de las respuestas con un nivel de significación de 0,05\%

La seroprevalencia contra Leptospira spp. en los caballos estudiados (85\%) es una de las más altas reportadas en el mundo. En Brasil, se han registrado las siguientes seroprevalencias: en São Paulo, 54 \% (23), en Paraibano, 16,2 \% (24), en Curitiba, 75,8 \% (25), en Río de Janeiro, 47,8 $\%$ (8), y en Paraná, 66,8 \% (26). En Suecia, se ha registrado $27 \%(27)$, en Corea, $25 \%$ (9), en Irán, 7,77\% (28), en Mongolia, 17,1\% (29), en Alemania, $17,2 \%$ (30), en Portugal, $37 \%$ (31), en Sudáfrica, 39,3 \% (32), en Australia, $35 \%$ (33), y en Etiopía, 44 \% (4). En la Sabana de Bogotá, se ha registrado 
una seroprevalencia de 40,4\% (34), en Santander, 66,7\% (35), y en la región del Meta y Guaviare, 76,6 \% (17).

En este caso, la alta serorreacción frente a varios serovares podría representar infecciones concomitantes y estar asociada con la frecuencia en que los caballos estudiados salían de las instalaciones, ya que ello favorece el contacto directo con otros caballos, y animales domésticos y silvestres (5). Asimismo, las variadas condiciones de pastoreo y confinamiento de los caballos podrían haber incrementado su exposición a leptospiras diseminadas por roedores, animales silvestres y otros huéspedes de mantenimiento presentes en el suelo, los pastos y las fuentes de agua $(3,7)$.

En este estudio, predominó la presentación subclínica de la leptospirosis: a pesar de que se registró una alta seroprevalencia, los caballos tenían una buena condición corporal y no presentaban los signos clínicos y los antecedentes característicos de la leptospirosis en los caballos adultos $(2,6)$ manejados bajo condiciones de confinamiento $(5,15)$. Asimismo, se encontraron títulos individuales de 1:800 o más en la MAT, hallazgo que, además de la presencia de animales asintomáticos, puede considerarse un indicativo de la presentación endémica de la leptospirosis en la población caballar evaluada (1). Teniendo en cuenta que los caballos del estudio pertenecen a la Policía Nacional, se recomienda el tratamiento antibiótico de los caballos positivos como medida de control de la infección, estrategia que se ha empleado en Croacia en todos los caballos utilizados para deporte y recreación (3).

Algunos mamíferos silvestres pueden actuar como huéspedes de mantenimiento de los serovares Djasiman y Shermani $(22,36)$, aspecto que recientemente fue reportado en chigüiros (Hydrochoerus hydrochaeris) de la región amazónica (37). El serovar Djasiman fue descrito por primera vez en Indonesia y en el sudeste asiático, donde se vinculó con leptospirosis en turistas (31), y también, se aisló de un feto canino abortado en Argentina (38). En este estudio, el serogrupo Djasiman fue el más frecuente en las remontas de Cali, Tuluá y Armenia, lo que coincide con reportes de Sudáfrica y Etiopía $(4,32)$.

En cuanto al serogrupo Shermani, varios autores sugieren que tiene poca importancia en la epidemiología de la leptospirosis $(25,28,30)$. No obstante, los caballos de las remontas en las cuales se reportó la presencia de especies silvestres, presentaron 3,3 veces más probabilidad de ser reactivos a este serogrupo en la prueba MAT. Este serogrupo también se asoció con un caso de leptospirosis humana que cursó con hemorragia intraalveolar, lo cual es indicativo de un cuadro clínico grave (31).

La alta seroprevalencia del serogrupo Shermani en los caballos de mayor edad de este estudio, sugiere su adaptación a estos animales y, tal vez, la persistencia de los títulos durante muchos años, por lo que existe la posibilidad de que los caballos sean huéspedes de mantenimiento de este serogrupo (26).

Algunos investigadores han reportado la presencia de leptospiruria crónica, inclusive, a lo largo de toda la vida en los caballos $(8,14)$. Asimismo, con la inoculación experimental de caballos con L. interrogans serovar Kinnenwicki, se registró la presencia de leptospiremia (entre dos y seis días) y de leptospiruria (durante cuatro semanas) después de la infección, lo cual indica que dichos animales podían diseminar la bacteria (39). En el estudio se obtuvo el crecimiento de espiroquetas en el $65 \%$ de los urocultivos, pero no se puede descartar su ausencia en las muestras negativas, porque la 
excreción de la bacteria por la orina en los huéspedes de mantenimiento es, en ocasiones, intermitente (20). La gran proporción de urocultivos positivos $(64,7 \%)$ sugiere la persistencia de las bacterias en los túbulos renales y la potencial importancia en su diseminación (14). Sin embargo, es conveniente hacer estudios complementarios en la población general de caballos, sobre todo teniendo en cuenta que en el presente estudio la prueba de PCR fue negativa en todos los casos.

Los resultados divergen en cuanto al aislamiento de leptospiras de las muestras de caballos mediante la técnica de PCR. Algunos investigadores de Brasil obtuvieron resultados positivos en una PCR cuantitativa con el gen $\operatorname{Sec} Y(40,41)$ y, en una convencional, con el gen LipL32 (8). Sin embargo, otros autores, también en Brasil, no lo lograron utilizando una PCR cuantitativa en caballos carretilleros (24), resultados que concuerdan con los del presente estudio y podrían relacionarse con fallas en el procedimiento de cultivo o de lectura (8), o con el hecho de que el muestreo no se hizo en la fase aguda de la infección (39), o porque se desconocían las rutas naturales de la infección en los caballos evaluados en este estudio (ya que, en una investigación previa, los animales infectados experimentalmente por vía subcutánea y ocular, no presentaron leptospiruria ni leptospiremia) (24), así como con la presencia de inhibidores de la PCR no detectados en la muestra (10).

En un estudio en Colombia, se amplificó el gen LipL32 a partir de muestras de orina humana y de animales domésticos (cerdos y perros), así como de agua y macerado de riñón de roedores sinantrópicos, y los resultados sugirieron que se daba una transmisión de leptospiras entre los animales, el ambiente y los humanos en la región evaluada (42).

Todavía no se ha verificado la idoneidad de los mecanismos celulares y moleculares para establecer la patogenia de las leptospiras (8). La proteína LipL32 representa hasta el $75 \%$ de la membrana externa de las leptospiras patógenas y su estudio ha sido relevante, dada su localización, su conservación y su importancia en la reacción inmunitaria de la bacteria, y porque está ausente en las leptospiras saprofitas (43).

El hecho de que no se detectara el ADN de los cultivos de espiroquetas en el presente trabajo, podría relacionarse con la presencia de leptospiras saprofitas. No obstante, la PCR de control de la extracción reveló que las muestras tenían ADN bacteriano, por lo que también es posible que la cantidad de leptospiras patógenas presentes en la orina fuera inferior a 100.000 bacterias $/ \mathrm{ml}$, cantidad necesaria para su detección con la prueba de PCR convencional (10). Además, según la Organización Mundial de Sanidad Animal (OIE), el que no se detecte la presencia de leptospiras en la orina de un animal no es suficiente para descartar la posibilidad de que sea portador renal crónico y solo indica que el caballo no excretaba cantidades detectables de leptospiras en el momento del examen (21).

En futuros estudios, lo ideal sería usar una PCR cuantitativa o técnicas diagnósticas que permitan la identificación completa de cepas de leptospira para establecer si son patógenas o saprofitas, así como la especie de Leptospira a la que pertenece la cepa y su serogrupo o serotipo. Entre dichas pruebas, se cuentan las de virulencia, de resistencia relativa a la 8-azaguanina, de actividad de la lipasa, de tolerancia a la sal, así como las de temperatura y contenido de $\mathrm{G}+\mathrm{C}$ en el $\operatorname{ADN}(21)$, aspecto que no fue objeto de esta investigación. 
Se puede concluir que la baja seroprevalencia de leptospirosis en el personal ocupacionalmente expuesto aquí analizado, podría asociarse con la implementación de medidas de prevención y el uso de elementos de protección personal.

Por otra parte, la alta seroprevalencia contra leptospiras en los caballos pone en evidencia la exposición natural a las bacterias, puesto que ningún animal había sido vacunado. Asimismo, los altos títulos hallados, el crecimiento de espiroquetas en el urocultivo y la presentación subclínica de la infección, indican un comportamiento endémico de la leptospirosis en la población evaluada. Los hallazgos sugieren que los caballos pueden comportarse como reservorios de las leptospiras, pero la dinámica de su mantenimiento, de su colonización persistente de los túbulos renales y de la subsiguiente eliminación de la bacteria por la orina, aún se desconoce, por lo que es necesario hacer estudios sistemáticos de detección de anticuerpos contra Leptospira spp. para establecer la exposición, la permanencia de títulos, la dinámica de los niveles de anticuerpos y los serogrupos infecciosos, entre otros aspectos.

\section{Agradecimientos}

A la Vicerrectoría de Investigaciones y Posgrados de la Universidad de Caldas, a la Universidad del Valle, al Proyecto de Formación de Talento Humano de Alto Nivel del Tolima y a la Policía Nacional por la financiación de la investigación.

\section{Referencias}

1. Levett PN. Leptospirosis: A forgotten zoonosis? Clin Appl Immunol Rev. 2004;4:435-48. https://doi.org/10.1016/j.cair.2004.08.001

2. Verma A, Stevenson B, Adler B. Leptospirosis in horse. Vet Microbiol. 2013;167:61-6. https://doi.org/10.1016/j.vetmic.2013.04.012.2013

3. Habus J, Persic Z, Spicic S, Vince S, Zrinka S, Milas Z, et al. New trends in human and animal leptospirosis in Croatia, 2009-2014. Acta Tropica. 2017;168:1-8. https://doi.org/10.1016/j.actatropica.2017.01.002

4. Tsegay K, Potts AD, Aklilu N, Lötter C, Gummow B. Circulating serovars of Leptospira in cart horses of central and southern Ethiopia and associated risk factors. Prev Vet Med. 2016;125:106-15. https://doi.org/10.1016/j.prevetmed.2016.01.009

5. Tadich TA, Tapia C, González D. Seroprevalence of Leptospira spp. in working horses located in the Central Region of Chile. J Equine Vet Sci. 2016;38:14-8.

https://doi.org/10.1016/j.jevs.2015.12.011

6. Hamond C, Martins G, Lilenbaum W. Subclinical leptospirosis may impair athletic performance in racing horses. Trop Anim Health Prod. 2012;44:1927-30. https://doi.org/10.1007/s11250-012-0158-5

7. Mwachui MA, Crump L, Hartskeerl R, Zinsstag J, Hattendorf J. Environmental and behavioural determinants of leptospirosis transmission: A systematic review. PLoS Negl Trop Dis. 2015;9:1-15. https://doi.org/10.1371/journal.pntd.0003843

8. Hamond C, Martins G, Lawson-Ferreira R, Medeiros MA, Lilenbaum W. The role of horses in the transmission of leptospirosis in an urban tropical area. Epidemiol Infect. 2013;141:335. https://doi.org/10.1017/S0950268812000416

9. Jung BY, Lee KW, Ha TY. Seroprevalence of Leptospira spp. in clinically healthy racing horses in Korea. J Vet Med Sci. 2010;72:197-201. https://doi.org/10.1292/jvms.09-0273

10. Picardeau M, Bertherat E, Jancloes M, Skouloudis AN, Durski K, Hartskeerl RA. Rapid tests for diagnosis of leptospirosis: Current tools and emerging technologies. Diagn Microbiol Infect Dis. 2014;78:1-8. https://doi.org/10.1016/j.diagmicrobio.2013.09.012

11. Levett PN, Morey RE, Galloway RL, Turner DE, Steigerwalt AG, Mayer LW. Detection of pathogenic leptospires by real-time quantitative PCR. J Med Microbiol. 2005;54:45-9. https://doi.org/10.1099/jmm.0.45860-0 
12. Kositanont U, Rugsasuk S, Leelaporn A, Phulsuksombati D, Tantitanawat S, Naigowit P. Detection and differentiation between pathogenic and saprophytic Leptospira spp. by multiplex polymerase chain reaction. Diagn Microbiol Infect Dis. 2007;57:117-22. https://doi.org/10.1016/j.diagmicrobio.2006.07.014

13. Hamond C, Martins G, Lilenbaum W, Madeiros MA. PCR detection of leptospiral carriers among seronegative horses. Vet Rec. 2012;171:105-6. https://doi.org/10.1136/vr.e5022

14. Levett PN. Leptospirosis. Clin Microbiol. 2001;14:296-326. https://doi.org/10.1128/CMR.14.2.296-326.2001

15. Agudelo-Flórez P, Restrepo-Jaramillo BN, Arboleda-Naranjo M. Situación de la leptospirosis en el Urabá antioqueño colombiano: estudio seroepidemiológico y factores de riesgo en población general urbana. Cad Saúde Pública. 2007;23:2094-102. https://doi.org/10.1590/S0102-311X2007000900017

16. Romero MH, Sánchez J, Hayek LC. Prevalencia de anticuerpos contra Leptospira en población urbana humana y canina del departamento del Tolima. Rev Salud Pública. 2010;12:268-75. https://doi.org/10.1590/S0124-00642010000200010

17. Rey-Riaño LA, Pineda-Rojas NF, Góngora-Orjuela A, Parra-Arango JL, Patiño-Burbano RE. Evaluación serológica a Leptospira spp. en equinos aparentemente sanos en municipios del Meta y Guaviare, Colombia. Revista Lasallista de Investigación 2015;12:154-61.

18. Troncoso-Toro I, Toro-Barros J, Guzmán-Cáceres A, Fuentealba-Ortega J, Wiethuchter CF. Evaluación serológica de Leptospira interrogans en equinos pertenecientes um centro equestre da província de Linares, Chile. Revista CES de Medicina y Zootecnia 2013;8:1017.

19. Scheaffer RL, Mendenhall W, Ott L. Elementos de muestreo. Madrid: Editorial Paraninfo, S.A.; 2006. p. 51

20. Astudillo-Hernández M, González-Rodríguez A, Batista-Santiesteban N, Mirabal-Sosa M, Menéndez-Hernández J. Estudio seroepidemiológico de la leptospirosis humana en el departamento del Valle del Cauca, Colombia. Revista Cubana de Medicina Tropical 2009;61:1-10.

21. Organización Mundial de Sanidad Animal (OIE). Manual de las pruebas de diagnóstico y de las vacunas para los animales terrestres (mamíferos, aves y abejas). Quinta edición. Paris: OIE; 2004. p. 1260. http://www.oie.int/doc/ged/d6508.pdf

22. Moreno N, Flórez PA. Aplicación de las pruebas de PCR convencional simple y múltiple para la identificación de Leptospira spp. en Colombia. Rev Peru Med Exp Salud Pública. 2010;27:548-56.

23. Langoni H, Da Silva A, Pezerico S, De Lima V. Anti-leptospire agglutinins in equine sera, from São Paulo, Goias, and Mato Grosso do sul, Brazil, 1996-2001. Journal of Venomous Animals and Toxins including Tropical Diseases 2004;10:207-18. https://doi.org/10.1590/S1678-91992004000300003

24. de Oliveira-Filho RB, Malta KC, Oliveira JM, Assis-Santana VL, Harrop MHV, Stipp DT, et al. Epidemiological analysis of Leptospira spp. infection in equids from the Brejo Paraibano microregion in Brazil. J Equine Vet Sci. 2014;34:407-14 https://doi.org/10.1016/j.jevs.2013.08.001

25. Finger MA, Barros Filho IR, Leutenegger C, Estrada M, Ullmann LS, Langoni $\mathrm{H}$, et al. Serological and molecular survey of Leptospira spp. among cart horses from an endemic area of human leptospirosis in curitiba, southern Brazil. Rev Inst Med Trop São Paulo. 2014;56:473-6. https://doi.org/10.1590/S0036-46652014000600003

26. Hashimoto VY, GonÇalves DD, da Silva FG, de Oliveira RC, Alves LA, Reichmann P, et al. Occurrence of antibodies against Leptospira spp. in horses of the urban area of Londrina, Paraná, Brazil. Rev Inst Med Trop São Paulo. 2007;49:327-30. https://doi.org/10.1590/S0036-46652007000500010

27. Båverud V, Gunnarsson A, Engvall EO, Franzén P, Egenvall A. Leptospira seroprevalence and associations between seropositivity, clinical disease and host factors in horses. Acta Vet Scand. 2009;51:1-10. https://doi.org/10.1186/1751-0147-51-15

28. Khousheh Y, Hassanpour A, Abdollahpour GR, Mogaddam S. Seroprevalence of leptospira infection in horses in ardabil-iran. Glob Vet. 2012;9:586-9. http://idosi.org/gv/GV9(5)12/14.pdf

29. Odontsetseg N, Boldbaatar D, Mweene AS, Kida H. Serological prevalence of Leptospira interrogans serovar Bratislava in horses in Mongolia. Vet Rec. 2005;157:518-9.

https://doi.org/10.1136/vr.157.17.518 
30. Pikalo J, Sattler T, Eichinger M, Loitsch A, Sun H, Schmoll F, et al. Occurrance of antibodies against Leptospira in horses in Middle Germany. Berl Munch Tierarztl Wochenschr. 2016;129:202-8.

31. Rocha T, Ellis WA, Montgomery J, Gilmore C, Regalla J, Brem S. Microbiological and serological study of leptospirosis in horses at slaughter: First isolations. Res Vet Sci. 2004;76:199-202. https://doi.org/10.1016/j.rvsc.2003.12.003

32. Simbizi V, Saulez MN, Potts A, Letter C, Gummow B. A study of leptospirosis in South African horses and associated risk factors. Prev Vet Med. 2016;134:6-15. https://doi.org/10.1016/j.prevetmed.2016.09

33. Wangdi C, Picard J, Tan R, Condon F, Dowling B, Gummow B. Equine leptospirosis in tropical Northern Queensland. Aust Vet J. 2013;91:190-7. https://doi.org/10.1111/avj.12038

34. Valencia C, Silva J. Prevalencia de Leptospira spp. en equinos en la sabana de Bogotá (tesis). Bogotá: Universidad de la Salle; 2007.

35. Bedoya-Ríos MA, Jaimes-Salcedo J, Molina-Sanguino LM. Prevalencia de Leptospira spp. en equinos de la vereda Guatiguara del municipio de Piedecuesta, Santander. Rev Electron Vet. 2013;14:1-6.

36. Vieira AS, Narduche L, Martins G, Schabib Péres IA, Zimmermann NP, Juliano RS, et al. Detection of wild animals as carriers of Leptospira by PCR in the Pantanal biome, Brazil. Acta Trop. 2016;163:87-9. https://doi.org/10.1016/j.actatropica.2016.08.001

37. de Albuquerque NF, Martins G, Medeiros L, Lilenbaum W, Ribeiro VM. The role of capybaras as carriers of leptospires in periurban and rural areas in the western Amazon. Acta Trop. 2017;169:57-61. https://doi.org/10.1016/j.actatropica.2017.01.018

38. Rossetti CA, Liem M, Samartino LE, Hartskeerl RA. Buenos Aires, a new Leptospira serovar of serogroup Djasiman, isolated from an aborted dog fetus in Argentina. Vet Microbiol. 2005;107:241-8. https://doi.org/10.1016/j.vetmic.2005.01.015

39. Yan W, Faisal SM, Divers T, McDonough SP, Akey B, Chang YF. Experimental Leptospira interrogans serovar Kinnewicki infection of horses. J Vet Intern Med. 2010; 24:912-7. https://doi.org/10.1111/j.1939-1676.2010.0507.x

40. Hamond C, Pestana CP, Rocha-de-Souza CM, Cunha LE, Brandao FZ, Medeiros MA, et al. Presence of leptospires on genital tract of mares with reproductive problems. Vet Microbiol. 2015;179:264-9. https://doi.org/10.1016/j.vetmic.2015.06.014

41. Hamond C, Martins G, Bremont S, Medeiros MA, Bourhy P, Lilenbaum W. Molecular characterization and serology of Leptospira kirschneri (Serogroup Grippotyphosa) isolated from urine of a mare post-abortion in Brazil. Zoonoses Public Health. 2016;63:191-5. https://doi.org/10.1111/zph.12224

42. Calderón A, Rodríguez V, Máttar S, Arrieta G. Leptospirosis in pigs, dogs, rodents, humans, and water in an area of the Colombian tropics. Trop Anim Health Prod. 2014;46:427-32. https://doi.org/10.1007/s11250-013-0508-y

43. Murray GL, Srikram A, Hoke DE, Wunder EA, Henry R, Lo M, et al. Major surface protein LipL32 is not required for either acute or chronic infection with Leptospira interrogans. Infect Immun. 2009;77:952-8. https://doi.org/10.1128/IAl.01370-08 